\title{
VIRCHOWS ARCHIV
}

FUR

\section{PATHOLOGISCHE ANATOMIE UND PHYSIOLOGIE \\ UND}

\section{FÜR KLINISCHE MEDIZIN}

HERAUSGEGEBEN

ron

JOHANNES ORTH

\author{
BAND 202 \\ MIT \& TAFELN UND 62 TEX'TFIGUREN
}

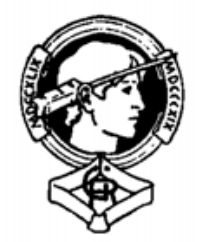

BERLIN W. 35

DRUCK UND VERLAG VON GEORG REIMER 1910 
